\title{
MICROBIOLOGICAL AND PHYSICAL-CHEMICAL EVALUATION OF THE WATER TABLE WELLS USED FOR HUMAN DRINKING, ALTA FLORESTA, MT, BRAZIL
}

\author{
CAMARGO, Mairo Fabio1; RACHOR, Clóvis Fernando²; MEDEIROS, Aline Goulart; \\ UMETSU, Ricardo Keichi ${ }^{4}$
}

1,2 Universidade do Estado de Mato Grosso (UNEMAT), Professor, Departamento de Engenharia Florestal, Graduando, Departamento de Ciências Biológicas, Rod. MT. 208, Km 147, C.P 324, CEP.: 78.580-000, Alta Floresta-MT. e-mail. mairocamargo@hotmail.com

\author{
${ }^{3}$ Escola Estadual de Ensino Fundamental e Médio Cecília Meireles, Av. Amazonas, s/n, CEP.: 78.580-000, Alta \\ Floresta-MT \\ 4 Universidade Federal de São Carlos, Programa de Pós-Graduação em Ecologia e Recursos Naturais-PPGERN/UFSCar.
}

\section{RESUMO}

A água é essencial para a existência e bem-estar do ser humano, devendo ser de boa qualidade como garantia da manutenção da vida. O presente trabalho objetivou determinar a qualidade da água dos poços superficiais utilizados para consumo humano. As análises físico-químicas e microbiológicas foram padronizadas conforme proposto na Portaria 518/2004, do Ministério da Saúde. As coletas foram realizadas no mês de fevereiro de 2008. Os bairros da Cidade de Alta Floresta-MT foram divididos em três setores. Em cada setor foram realizadas 20 amostragens. Os parâmetros físico-químicos e microbiológicos avaliados foram: cor, turbidez, $\mathrm{pH}$, cloro residual, coliformes totais e Escherichia coli. $\mathrm{O} \mathrm{pH}$ da maioria das amostras estava em desacordo com a legislação vigente $(<6,0)$. O cloro residual livre não foi observado em nenhuma amostra. A cor e a turbidez das amostras demonstraram valores de acordo com a recomendação da legislação em vigor (< $15 \mu \mathrm{H},<5,0 \mathrm{uT})$, respectivamente. Foram encontrados coliformes totais e Escherichia coli em todas as amostras. Todas as amostras analisadas, no que se refere às características microbiológicas, foram classificadas como impróprias para consumo humano.

Palavras-chave: Qualidade da Água, Padrões físico-químicos, Contaminação microbiológica.

\section{ABSTRACT}

Water is essential for the existence and well-being of humanity and should be of good quality to ensure the maintenance of life. The present work aim to determine the quality of the well water used for human consumption. The physical-chemical and microbiological analysis (turbidity, $\mathrm{pH}$, residual chlorine, total coliforms and Escherichia coli) were carried out according to the Government directive MS 518/2004 of the Brazilian Ministry of Health. The samples have been carried out in February, 2008. The neighborhoods of Alta Floresta were divided into three sections. In each section were collected 20 samples. The $\mathrm{pH}$ of most samples was less than 6.0, disagreeing with the Brazilian directive. There was no free chlorine residual in the samples. Color and turbidity showed values $(<15 \mu \mathrm{H}$ and $<5,0 \mathrm{uT}$, respectively) according to Brazilian directive. The total coliform and Escherichia coli were found in all samples. According to the microbiological analysis, all samples were classified as inappropriate for human consumption.

Keywords: Water quality, Physical-chemical patterns, Microbiological contamination. 


\section{Introdução}

A água é essencial para a existência e bem-estar do ser humano, devendo estar disponível em quantidade suficiente e de boa qualidade como garantia da manutenção da vida, sendo ingerida em quantidade superior a todos os outros alimentos e imprescindível para a higiene (FREITAS et al., 2002).

No Brasil, os Padrões de qualidade da água para consumo humano são regidos pela portaria $\mathrm{n}^{\circ} 518$ de 25 de março de 2004, do Ministério da Saúde (MS), que define os valores máximos e mínimos permissíveis para as característica microbiológicas, físicas e químicas de água potável (BRASIL, 2004).

A água para consumo humano pode ser obtida de diferentes fontes. Uma dessas é o manancial subterrâneo que possibilita a captação de águas do aquífero não confinado ou livre, sendo um dos recursos mais utilizados pela população de baixo poder aquisitivo, em função do baixo custo e pela facilidade de perfuração (SILVA e ARAÚJO, 2003).

Segundo Freitas (2001) e Silva \& Araújo (2003), as fontes de contaminação antropogênica em águas subterrâneas estão geralmente associadas ao esgoto doméstico, industriais e ao chorume oriundo de aterros de lixo que contaminam os lençóis freáticos com microorganismos patogênicos.

De acordo com Carvalho (1999), microrganismos patogênicos não se reproduzem e nem vivem muito tempo na água. Podem ser encontrados porque foram introduzidas através de esgotos ou resíduos que contenham dejetos humanos. Uma vez expelidos para o ambiente externo, vivem por pouco tempo, embora o suficiente para que sejam ingeridos por outra pessoa, que se tornará hospedeiro e poderá adquirir a doença.

Do ponto de vista da saúde pública, o teste de coliformes é o mais importante para determinar a presença de Escherichia coli, pois a sua presença significa que provavelmente se encontre microrganismos patogênicos produtores de enfermidades hídricas (CARVALHO, 1999).

Este trabalho teve por objetivo determinar a qualidade da água dos poços superficiais, utilizados para consumo humano na cidade de Alta Floresta-MT, através de análises físico- químicas ( $\mathrm{pH}$, cor, turbidez, cloro residual livre) e microbiológicas (Coliformes totais e Escherichia coli).

\section{MATERIAL E MÉTODOS}

A área do estudo compreendeu a cidade de Alta Floresta, localizada no extremo norte do Estado de Mato Grosso, cerca de $870 \mathrm{Km}$ da capital Cuiabá. Segundo IBGE, (2000) possui população de 46.982 habitantes, sendo residentes na zona urbana 37.287 pessoas. O Município está localizada nas coordenadas geográficas $09^{\circ} 53^{\prime} 02$ 'S e $56^{\circ} 14^{\prime} 38^{\prime \prime} W$. De acordo com a classificação de Köppen, a região apresenta clima do tipo Awi, com temperaturas variando entre $20^{\circ}$ a $38^{\circ} \mathrm{C}$. A precipitação média anual pode atingir $2.750 \mathrm{~mm}$ (IPED, 2001).

As coletas foram realizadas no mês de fevereiro de 2008, em residências que possuíam poços superficiais como fonte única de abastecimento de água. Segundo GVA, (2007) o município de Alta Floresta possui 14.167 residências e, em Fevereiro de 2008, apenas 9.046 possuíam ligação de água tratada (informação particular - AGUAS DE ALTA FLORESTA LTDA, 2008).

Diante destes números, 5.121 (36,14\%) residências Altaflorestensses não possuem ligação de água tratada, mesmo existindo rede de distribuição em todos os bairros do município. O município de Alta Floresta possuía a época do estudo 30 bairros na região urbana. Estes bairros foram distribuídos em três setores, os quais foram denominados setor 1, setor 2, e setor 3 . Em cada setor foram realizadas 20 amostragens, totalizando 60 amostras.

As residências que não possuem ligação de água tratada foram identificadas pelo mapa/rota utilizado pela empresa Águas de Alta Floresta LTDA, para localização dos lotes no município.

Os parâmetros físico-químicos e microbiológicos analisados foram: $\mathrm{pH} ; \mathrm{CRL}$ (Cloro Residual Livre); Cor; turbidez; Coliformes totais e Escherichia coli. Para medição do $\mathrm{pH}$ utilizou-se um peagâmetro de bancada, marca Policontrol, modelo $\mathrm{pH} 250$ digital, calibrado com soluções tampão, marca Synth, de pH 4.0 e pH 7.0. A determinação do teor de $\mathrm{CRL}$, se deu através de comparador colorimétrico com escala de 0,1 a 3,0 mg. $\mathrm{L}^{-1}$. 
A turbidez foi determinada através de um Turbidímetro Nefelométrico Digital, modelo AP 2000, Policontrol, Calibrado em NTU. Para a determinação da cor, foi utilizado o colorímetro NesslerQuant 200, com disco colorimétrico, escala de 0 a $50 \mathrm{uH}$, da Policontrol. As análises microbiológicas foram realizadas pelo método Colilert $囚$. As amostras de água dos poços foram coletadas nas saídas das bombas de recalque, antes de chegar a qualquer reservatório. As bombas foram acionadas aproximadamente três minutos antes da coleta, tempo suficiente para eliminar a água acumulada na tubulação.

Todas as análises foram realizadas no Laboratório da Empresa Águas de Alta Floresta Ltda.

\section{RESULTADOS E DISCUSSÃO}

A tabela 1 ilustra as características dos poços onde foram coletadas as amostras de água, conforme informações prestadas pelos proprietários das residências que fizeram parte do estudo. A análise de variância dos resultados demonstrou não ocorrer diferenças significativas $(p>0,05)$ dos parâmetros analisados entre os setores estudados.

Os resultados demonstraram que, em geral, a água encontra-se com acidez elevada. Os valores encontrados nas análises do $\mathrm{pH}$ (Tabela 2), indicaram que $85 \%$ das amostras do setor $1,95 \%$ das amostras do setor 2 e $90 \%$ das amostras do setor 3 , apresentaram valores de potencial hidrogeniônico inferiores àqueles preconizados na legislação vigente, estando, portanto, em desacordo com os valores de $\mathrm{pH}$ recomendado pela portaria $518 / 2004$ do MS, que estabelece o intervalo de 6,0 a 9,5 como ideais.

Conforme Freitas et al., (2001) o que pode explicar o $\mathrm{pH}$ abaixo de 6,0 na maioria das amostras é a infiltração do líquido proveniente das fossas no lençol superficial, pois este em contato com o lençol freático altera o $\mathrm{pH}$ da água subterrânea, uma vez que a decomposição da matéria orgânica por microrganismos leva à formação de variados ácidos orgânicos.

Em relação à cor da água das amostras analisadas (Tabela 3), todas apresentaram valores que são aceitos pela legislação vigente, apresentando um mínimo de 2,0 uH e um máximo de 15,0 uH. A cor da água é influenciada pela matéria orgânica e por metais, como o ferro e o manganês. A sua medida é de fundamental importância, visto que água com cor elevada provoca rejeição, devido ao aspecto visual, por parte dos consumidores (BRASIL, 2006)

A turbidez da água dos poços analisados variou entre 0,02 e 2,75 UNT, com média 0,16 UNT. Todas as amostras analisadas apresentaram valores dentro da faixa de aceitabilidade estabelecida pela legislação (Tabela 4). Em nenhuma amostra foi observada concentração de cloro residual livre, apesar de $20 \%$ dos moradores do setor $1 ; 30 \%$ do Setor 2 e $25 \%$ do setor 3 afirmarem que adicionam cloro, na forma de solução de hipoclorito de sódio $(2,5 \% \mathrm{v} / \mathrm{v})$ diretamente no poço. Isso pode ser explicado pelo fato de que na presença de material orgânico e outros compostos oxidáveis o cloro será consumido em parte ou totalmente. (MEYER, 1994)

Quanto à avaliação da qualidade microbiológica da água, os resultados das análises demonstraram que todas as amostras encontravam-se contaminadas por Coliformes totais e Escherichia coli. A legislação estabelece que em água para consumo humano, incluindo fontes individuais como poços, não é permitida a presença de Escherichia coli. Em relação a coliformes totais, a legislação preconiza que em amostras procedentes de poços tolera-se a presença de coliformes totais, na ausência de Escherichia coli.

Já foram realizados outros estudos em nossa região por Silva (2002), Rhoden (2004) e Camargo \& Paulosso (2007) com águas de poços, e todos os trabalhos evidenciaram contaminação por Coliformes totais e Escherichia coli. A contaminação dessas águas pode estar sendo provocada pelas fossas domésticas, através da infiltração do líquido do próprio esgoto in natura.

\section{CONCLUSÕES}

A água dos poços superficiais estudados encontram-se impróprias para consumo humano, de acordo com os padrões propostos pela portaria 518/2004 do MS.

Os resultados dos trabalhos relacionados à qualidade das águas de poços superficiais da região, indicam que o aqüífero superficial pode estar contaminado por esgoto doméstico. 


\section{REFERÊNCIAS BIBLIOGRÁFICAS}

1. BRASIL. Portaria $n^{\circ} 518$, de 25 de março de 2004. O Ministério da Saúde aprova normas e padrões de potabilidadeda água destinada ao consumo humano. Diário Oficial, Brasília, 25 março 2004, Seção 1, p.266-70.

2. BRASIL. Fundação Nacional de Saúde. Manual prático de análise de água. 2 ed. rev. Brasília: Funasa, p. 146, 2006a.

3. BRASIL. Fundação Nacional de Saúde. Manual de saneamento. 3 ed. rev. Brasília: Funasa, p. 407, 2006b.

4. CAMARGO, M. F.; PAULOSSO, L. V. Avaliação qualitativa da contaminação microbiológica das águas de poços por coliformes totais e Escherichia coli no município de Carlinda - MT. Revista Semina Biológicas/Saúde, Londrina, v.30, n.1, 2009.

5. CARVALHO, E. P. Microbiologia de alimentos. 1. ed. UFLA/FAEPE: Universitária, p.128, 1999.

6. FREITAS, M. B.; BRILHANTE, O. M.; ALMEIDA, L. M. Importância da análise de água para a saúde pública em duas regiões do Estado do Rio de Janeiro: enfoque para coliformes fecais, nitrato e alumínio. Caderno de Saúde Pública, Rio de Janeiro, v.17, n.3, p.651-660, mai./jun. 2001.

7. FREITAS, V. P. S.; BRÍGIDO, B. M.; BADOLATO. M. I. C.; ALABURDA, J. Padrão físico-químico da água de abastecimento público da região de
Campinas. Rev. Inst. Adolfo Lutz, v. 61, n.1, p.51-58, 2002

8. GVA/PMAF (Gerência de Vigilância Ambiental/Prefeitura Municipal de Alta Floresta) GVA: Alta Floresta, 2007.

9. IBGE (Instituto Brasileiro de Geografia Estatística) Censo Demográfico 2000. Disponível em <http://www.ibge.gov.br>. Acesso em: 14 Nov. 2007.

10. IPED - Instituto de Pesquisa, Desenvolvimento e Gestão. Perfil Diagnóstico do Município de Alta Floresta. Cuiabá, 2001.

11. MEYER, S. T. O uso de cloro na desinfecção de águas, a formação de trihalometanos e os riscos potenciais à saúde pública. Caderno de Saúde Pública, Rio de Janeiro, v.10, n.1, p.99110, jan./mar. 1994.

12. RHODEN, A. M. Análise bacteriológica de poços urbanos de Alta Floresta Mato Grosso. 2004. 82 f. Monografia Universidade do Estado de Mato Grosso, Alta Floresta, 2004.

13. SILVA, L. K. Avaliação bacteriológica da qualidade da água do bairro boa esperança no município de Alta Floresta, MT. 2002. 35 f. Monografia Universidade do Estado de Mato Grosso, Alta Floresta, 2002.

14. SILVA, R. C. A.; ARAÚJO, T. M. Qualidade da água do manancial subterrâneo em áreas urbanas de Feria de Santana (BA). Ciência \& Saúde Coletiva, v.8, n.4, p.1019-1028, 2003. 
Tabela 1. Característica dos poços onde foram coletadas as amostras de água para análises laboratoriais.

\begin{tabular}{|c|c|c|c|}
\hline Característica & Setor $1 \%$ & Setor $2 \%$ & Setor $3 \%$ \\
\hline \multicolumn{4}{|l|}{ Idade do poço } \\
\hline Até 5 anos & 60 & 20 & 15 \\
\hline$>5$ a 10 anos & 10 & 25 & 30 \\
\hline$>10$ a 15 anos & 15 & - & 20 \\
\hline$>15$ anos & 15 & 40 & 25 \\
\hline Não soube informar & - & 15 & 10 \\
\hline \multicolumn{4}{|c|}{ Profundidade do poço } \\
\hline Até 10 metros & 30 & 15 & 40 \\
\hline$>10$ a 20 metros & 65 & 45 & 60 \\
\hline$>20$ a 30 metros & - & - & - \\
\hline$>30$ metros & 5 & 15 & - \\
\hline Não soube informar & - & 25 & - \\
\hline \multicolumn{4}{|c|}{ Distancia entre o poço e a fossa } \\
\hline Até 30 metros & 100 & 85 & 95 \\
\hline$>30$ metros & - & 10 & 5 \\
\hline Ligação esgoto & - & 5 & - \\
\hline
\end{tabular}

$\%$ (resultado percentual proporcional)

Tabela 2. Resultado das análises do pH das amostras de águas de poços superficiais dos setores da região urbana de Alta Floresta-MT.

\begin{tabular}{l|c|c|c}
\hline Parâmetro pH & Setor $\mathbf{1} \%$ & Setor $\mathbf{2} \%$ & Setor $\mathbf{3} \%$ \\
\hline 6,0 a $9,5^{*}$ & 15 & 5 & 10 \\
\hline$<6,0$ & 85 & 95 & 90 \\
\hline$>9,5$ & - & - & - \\
\hline
\end{tabular}

* Padrão de aceitação para consumo humano recomendado pela portaria $n^{\circ} .518 / 2004$.

Tabela 3. Análises da cor das amostras de águas de poços estudados no mês fevereiro de 2008, Alta Floresta, MT.

\begin{tabular}{c|c|c|c|c}
\hline Parâmetros & Setores & Mínimo & Máximo & Média \\
\hline \multirow{3}{*}{ Cor: $<15 \mathrm{uH}^{*}$} & $\mathbf{1}$ & 2,5 & 10,0 & 3,13 \\
\cline { 2 - 5 } & $\mathbf{2}$ & 2,5 & 15,0 & 3,50 \\
\cline { 2 - 5 } & $\mathbf{3}$ & 2,5 & 7,5 & 3,38 \\
\hline
\end{tabular}

* Padrão de aceitação para consumo humano recomendado pela portaria nº.518/2004. 
Tabela 4. Análises da turbidez das amostras de águas de poços estudados no mês fevereiro de 2008, Alta Floresta, MT.

\begin{tabular}{c|c|c|c|c}
\hline Parâmetros & Setores & Mínimo & Máximo & Média \\
\hline \multirow{3}{*}{ Turbidez: $<5$ uT* $^{*}$} & $\mathbf{1}$ & 0,02 & 2,75 & 0,16 \\
\cline { 2 - 5 } & $\mathbf{2}$ & 0,02 & 0,02 & 0,02 \\
\cline { 2 - 5 } & $\mathbf{3}$ & 0,02 & 0,02 & 0,02 \\
\hline
\end{tabular}

* Padrão de aceitação para consumo humano recomendado pela portaria $n^{\circ} .518 / 2004$. 